\title{
The anti-apoptotic BAG3 protein is expressed in lung carcinomas and regulates small cell lung carcinoma (SCLC) tumor growth
}

\author{
Gennaro Chiappetta ${ }^{1, *}$, Anna Basile ${ }^{2,3, *}$, Antonio Barbieri, Antonia Falco ${ }^{2,3}$, \\ Alessandra Rosati ${ }^{2,3}$, Michelina Festa ${ }^{2,3}$, Rosa Pasquinelli ${ }^{1}$, Daniela Califano ${ }^{1}$, \\ Giuseppe Palma4, Raffaele Costanzo5 , Daniela Barcaroli6, Mario Capunzo7, Renato \\ Franco $^{8}$, Gaetano Rocco9, Maria Pascale ${ }^{2,3}$, Maria Caterina Turco ${ }^{3,7}$, Vincenzo De \\ Laurenzi ${ }^{3,6}$ and Claudio Arra ${ }^{4}$ \\ 1 Functional Genomic Unit, Istituto Nazionale per lo Studio e la Cura dei Tumori "Fondazione Giovanni Pascale", IRCCS, \\ Naples, Italy \\ 2 Department of Pharmacy, University of Salerno, Fisciano, Italy \\ ${ }^{3}$ BIOUNIVERSA S.r.l., University of Salerno, Fisciano, Italy \\ ${ }^{4}$ Animal Facility Unit, Istituto Nazionale per lo Studio e la Cura dei Tumori "Fondazione Giovanni Pascale", IRCCS, Naples, \\ Italy \\ ${ }^{5}$ Medical Oncology Unit, Thoraco-Pulmonary Department, Istituto Nazionale per lo Studio e la Cura dei Tumori "Fondazione \\ Giovanni Pascale", IRCCS, Naples, Italy \\ ${ }^{6}$ Department of Experimental and Clinical Sciences, University G. D'Annunzio and Fondazione G. D'Annunzio, Ce.S.I., Chieti, \\ Italy \\ ${ }^{7}$ Department of Medicine and Surgery, University of Salerno, Fisciano, Italy \\ 8 Pathology Unit, Istituto Nazionale per lo Studio e la Cura dei Tumori "Fondazione Giovanni Pascale", IRCCS, Naples, Italy \\ ${ }^{9}$ Thoracic Surgery Unit, Thoraco-Pulmonary Department, Istituto Nazionale per lo Studio e la Cura dei Tumori "Fondazione \\ Giovanni Pascale", IRCCS, Naples, Italy \\ * These Authors contributed equally to the work
}

Correspondence to: Maria Caterina Turco, email: mcturco@unisa.it

Keywords: BAG3, SCLC, NSCLC, tumor growth, apoptosis

Received: July 08, $2014 \quad$ Accepted: July 25, $2014 \quad$ Published: July 25, 2014

This is an open-access article distributed under the terms of the Creative Commons Attribution License, which permits unrestricted use, distribution, and reproduction in any medium, provided the original author and source are credited.

\section{ABSTRACT}

BAG3, member the HSP70 co-chaperones family, has been shown to play a relevant role in the survival, growth and invasiveness of different tumor types. In this study, we investigate the expression of BAG3 in 66 specimens from different lung tumors and the role of this protein in small cell lung cancer (SCLC) tumor growth. Normal lung tissue did not express BAG3 while we detected the expression of BAG3 by immunohistochemistry in all the 13 squamous cell carcinomas, 13 adenocarcinomas and 4 large cell carcinomas. Furthermore, we detected BAG 3 expression in 22 of the 36 SCLCs analyzed. The role on SCLC cell survival was determined by downregulating BAG3 levels in two human SCLC cell lines, i.e. $\mathrm{H69}$ and $\mathrm{H446}$, in vitro and measuring cisplatin induced apoptosis. Indeed down-regulation of BAG3 determines increased cell death and sensitizes cells to cisplatin treatment. The effect of BAG3 down-regulation on tumor growth was also investigated in an in vivo xenograft model by treating mice with an adenovirus expressing a specific bag 3 siRNA. Treatment with bag3 siRNA-Ad significantly reduced tumor growth and improved animal survival. In conclusion we show that a subset of SCLCs over express BAG3 that exerts an antiapoptotic effect resulting in resistance to chemotherapy.

\section{INTRODUCTION}

Lung cancer is the leading cause of cancer-related deaths worldwide, accounting for over 200,000 new cases and over 160,000 deaths per year in the United States, the most aggressive form being small cell lung cancer (SCLC) that accounts for $>12 \%$ of all lung cancer diagnoses. In fact, SCLC patients have a median survival 
Table 1: Immunohistochemical analysis of BAG3 expression in normal and pathological human lung tissues

\begin{tabular}{|c|c|c|c|c|c|}
\hline Histological type & $\begin{array}{c}\text { N. of total cases } \\
\text { analized }\end{array}$ & \multicolumn{4}{|c|}{ BAG3 staining score* } \\
\hline & & 0 & 1 & 2 & 3 \\
\hline Normal lung tissue & 3 & 3 & & & \\
\hline Squamous cell carcinoma & 13 & 0 & 2 & 5 & 6 \\
\hline Adenocarcinoma & 13 & 0 & 4 & 7 & 2 \\
\hline Large cell carcinoma & 4 & 0 & 1 & 1 & 2 \\
\hline Small cell lung cancer & 36 & 14 & 10 & 8 & 4 \\
\hline
\end{tabular}

*Human lung specimens were stained with anti-BAG3 polyclonal antibody. The percentage of malignant cells stained was scored from 0 to 3 : 0 , no positive cells; $1+,<10 \%$ of positive cells; $2+, 11-50 \%$ of positive cells; $3+, 51-100 \%$ of positive cells.

of 15-20 months and 5-year survival below 15\% [1]. Treatment of SCLC is challenging, with a short diseasefree survival after 1 st line therapy $[1,2]$. It is therefore of uttermost importance to gain a deeper understanding of the molecular events involved in SCLC tumorigenesis and progression in order to identify novel potential targets for therapy.

Bcl2-associated athanogene 3 (BAG3) belongs to a family of co-chaperones known to interact with the ATPase domain of the heat shock protein 70 (Hsp70) through the structural domain known as BAG domain (110-124 amino acids). In addition, BAG3 contains a WW domain, a proline-rich region (PXXP), and two conserved IPV (Ile-Pro-Val) motifs, that can also mediate binding to other proteins. While BAG3 can be induced in response to stress in cells of various origin it is constitutively expressed only in a few, including skeletal muscle and the heart. Importantly it is has also been shown to be constitutive in several primary tumors and tumor cell lines (pancreatic cancer, melanoma, leukemias, and others) [3, $4]$ and has been shown to play an important role in tumor biology $[3,4,5,6,7,8]$. It has been suggested that its role in tumors is due to its anti-apoptotic properties in fact BAG3 has been shown to protect cells from death through a number of mechanisms that in general involve interaction with apoptosis- regulating proteins, including the IKK gamma subunit of the NF- $\kappa \mathrm{B}$ - activating complex IKK [5], Bax [9], BRAF [10] and others [3].

Figure 1: Immunohistochemical analysis of BAG3 expression in normal and neoplastic lung samples. Paraffin sections from 33 NSCLCs, 36 SCLCs and 3 normal lung specimens were analyzed by immunohistochemistry using anti-BAG3 rabbit polyclonal antibody. A) Normal lung tissue sample showing no immunoreactivity for BAG3 (200x). B) Lung adenocarcinoma showing BAG3 cytoplasmic staining (200x). C) Squamous cell carcinoma sample showing cytoplasmic BAG3 staining (200x). D) Immunostaining of the same squamous cell carcinoma sample as in panel $\mathrm{C}$ stained without the primary antibody (200x). E) SCLC sample showing BAG3 cytoplasmic staining (200x). F) SCLC sample negative for BAG3 protein expression (200x).
Here we investigated BAG3 expression in SCLCs and its role in tumorigenesis in a xenograft mouse model. Our data suggest that indeed BAG3 is a potential target in a subset of tumors that express it.

\section{RESULTS}

\section{Immunohistochemical analysis of BAG3 expression in human lung neoplastic samples}

We analyzed BAG3 expression in 69 samples (36 small cell lung cancers, 13 squamous cell carcinomas, 13 adenocarcinomas, 4 large cell carcinomas and 3 normal lung samples as control) by immunoistochemistry (IHC), using an anti-BAG3 polyclonal antibody (TOS-2). As expected no BAG3 expression was detected in normal lung while all the NSCLC and 22 out of the 36 SCLC
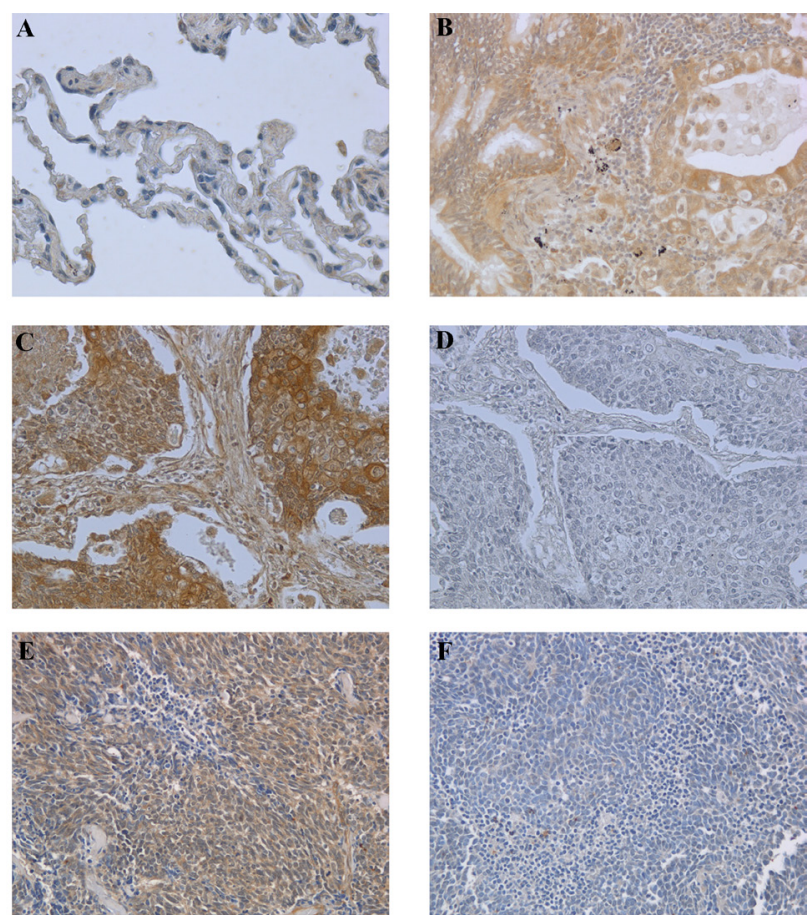
samples were BAG3- positive (Table 1 and Fig.1). Positive tumor samples showed a cytoplasmic staining in the majority of the cells.

\section{Effect of BAG3 down-modulation on SCLC cell apoptosis}

We then investigated the possibility that in BAG3 positive SCLCs this protein played a pro-survival role as reported for other tumor types $[3,4]$. To this end we first evaluated BAG3 expression by western blot in five human SCLC cell lines. As shown in Fig. 2A, H69 and H446 cell lines displayed the highest BAG3 protein levels and were chosen for the subsequent experiments to test if BAG3 silencing sensitized cells to cisplatin treatment. Both cell lines were transfected with a bag3- specific small interfering (si) RNA or with a non targeted (NT) siRNA. As shown in figures $2 \mathrm{~B}$ and $\mathrm{C}$ transfection with $200 \mathrm{nM}$ of bag3 specific siRNA resulted in silencing of BAG3 in both cell lines. As shown in figure $3 \mathrm{~B}$ and $\mathrm{D}$ silencing of BAG3 results in increased response to cisplatin with an increase in both cell lines of almost $40 \%$ of apoptosis after 48 hours of treatment with a $100 \mu \mathrm{M}$ cisplatin. Furthermore, BAG3 silencing in $\mathrm{H} 446$ results also a significant increase of basal apoptosis (Fig. 3D).

These results indicate that down-regulation of BAG3 stimulates apoptosis in SCLC cells in vitro.
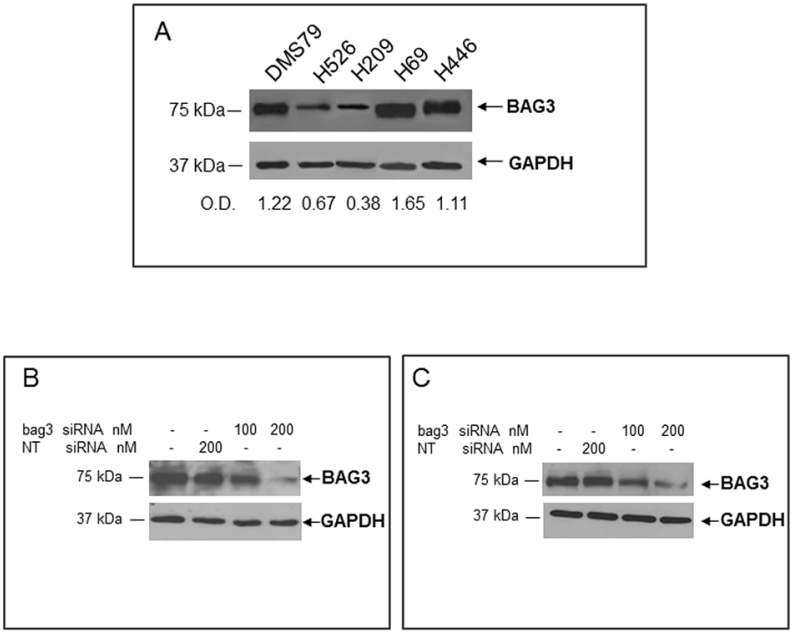

Figure 2: Analysis of BAG3 protein levels in human SCLC cell lines. A) Total protein extracts obtained from DMS79, H526, H209, H69 and H446 cell lines were analyzed by western blot using an anti-BAG3 polyclonal antibody. Densitometry data of samples are expressed as fractions of BAG3/GAPDH. H69 cells (B) and H446 cells (C) were transfected with a bag3-specific (bag3 siRNA) (100 and 200 $\mathrm{nM})$ or a NT siRNA (200 nM). After $72 \mathrm{hrs}$ BAG3 protein levels were analyzed by western blot using an anti-BAG3 polyclonal antibody. Anti-GAPDH antibody was used as loading control.

\section{Down-regulation of BAG3 reduces in vivo tumor growth and induces apoptosis}

Since in vitro data showed that down-regulation of BAG3 induces apoptosis in SCLS cells, we investigated the effects of bag3 siRNA-Ad treatment on tumor growth and apoptosis in vivo. As shown in Fig. 4A, we observed that intra-tumoral injection of bag3 siRNA-Ad was able to reduce in vivo tumor growth after 44 days of treatment as compared to the scramble-treated (scr siRNA-Ad) and control groups $(\mathrm{p}<0.001)$. Accordingly, mice treated with bag3 siRNA-Ad survived longer than control (PBS) and scr siRNA-Ad-treated mice $(\mathrm{p}<0.05)$ (Fig. 4B). Western blot and immunohistochemical analysis of tumor samples from xenografts treated for 12 days with bag 3 siRNA-Ad specifically confirm a reduction of BAG3 protein levels (Fig. 5 A, B).

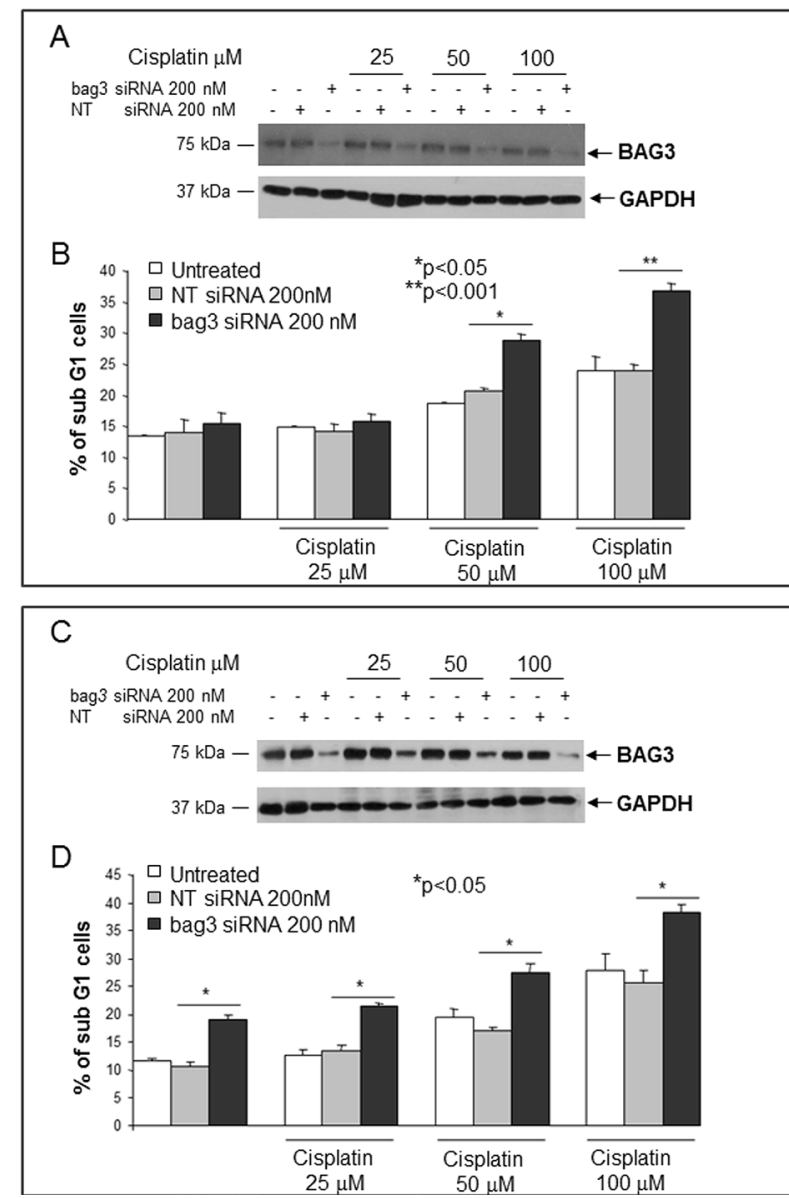

Figure 3: Effect of BAG3 down-regulation on SCLC cell apoptosis. H69 (A, B) or H446 (C, D) cells were transfected with bag3 siRNA (200 nM) or with NT siRNA (200 $\mathrm{nM}$ ) and after $48 \mathrm{hrs}$ treated with different doses of Cisplatin $(25,50,100$ microM) for $48 \mathrm{hrs}$. Cells were then collected and labeled with propidium iodide and analyzed by flow cytometry (B, D). Total protein extracts of cells treated as described above were analyzed by western blot using an anti-BAG3 polyclonal antibody. Anti-GAPDH antibody was used as loading control (A, C). $* \mathrm{p}<0.05 ; * * \mathrm{p}<0.001$. 
Evaluation of apoptosis using the terminal deoxynucleotidyl transferase (TdT) FragELTM DNA fragmentation detection kit, an analogue of the TUNEL method, shows that intra-tumoral injection of bag3 siRNA-Ad induced massive apoptotic cell death in tumor cells (Figure 6C).

\section{DISCUSSION}

Molecular classification of lung cancer has allowed targeted chemotherapeutic strategies. The understanding of the role of gene mutations (EGFR, K-RAS and MET), gene fusions (ALK) and rearrangements (ROS-1), has improved the management of non-small-cell lung cancer patients [11]. We suggest that evaluation of BAG3 expression might be a potentially useful classification tool for SCLCs.

BAG3 is an anti-apoptotic protein that has been shown to sustain cell survival in a variety of tumor types $[5,6,9,10]$, and indeed its down-regulation appears to induce cell apoptosis and impair tumor growth also in SCLC cells suggesting that it may represent a novel target for therapy in positive tumours.

A

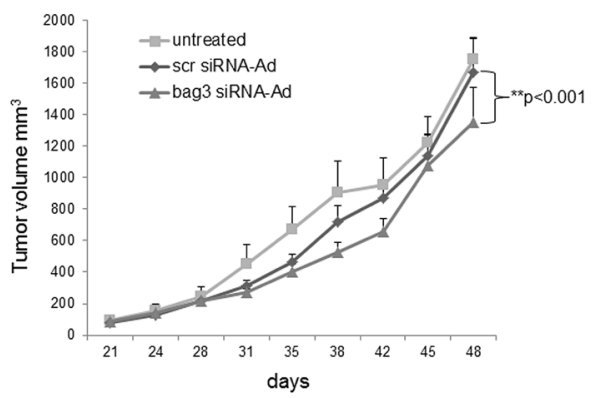

B

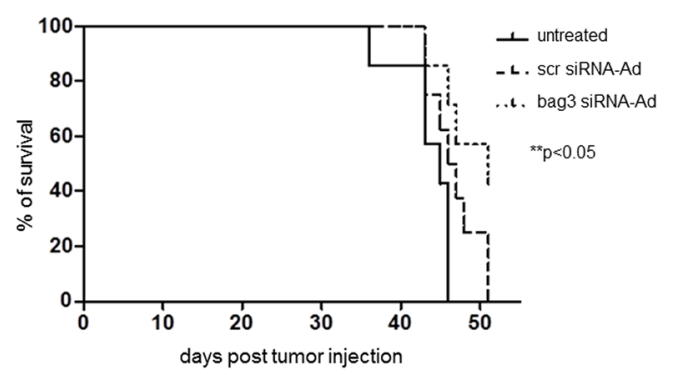

Figure 4: BAG3 down-regulation reduces tumor growth and increases animal survival in a xenograft model. H69 cells $\left(3 \times 10^{6}\right)$ were injected subcutaneously onto the back of six/eight-week-old female athymic nude-Foxn1nu/ nu mice. Two weeks later $\left(100 \mathrm{~mm}^{3}\right)$, animals were randomized into three groups (8 animals per group) and control PBS $(100 \mu \mathrm{l}-$ untreated), bag3 siRNA-Ad or scrRNA-Ad $\left(10^{8} \mathrm{pfu} / 100 \mu \mathrm{l}\right)$ were injected in the tumors twice a week. A) Tumor size was measured every week using a caliper in bag3 siRNA-Ad, scr siRNA-Ad treated or untreated mice. ${ }^{*} p<00.001$. B) KaplanMeier analysis of animal survival. ${ }^{*} \mathrm{p}<0.05$.
The pro-survival role of BAG3 in tumors largely relies on its ability to interact with different partners, some of which are selectively involved in the growth of specific tumor types [4]. The molecular mechanisms and the proteins involved in BAG3 pro-survival function in SCLCs are still unknown and require further studies. Recent reports indicate a relevant role for the MET signaling pathway in SCLC biology [12, 13, 14, 15]. Indeed, MET receptor phosphorylation induced by HGF is associated to the hyperexpression of mesenchymal markers and chemoresistance that result in a poor prognosis in SCLC patients [14, 15]. Furthermore, MET receptor signaling leads to the activation of $\mathrm{PI} 3 \mathrm{~K}-\mathrm{Akt}$ signaling, Ras-MAP kinase cascade, STAT3 and NF$\kappa \mathrm{B}$ activation, promoting cell survival, proliferation and invasiveness [16]. Some of these signaling proteins, including NF- $\kappa \mathrm{B}$ factors [5], RAF family proteins [10] and the downstream kinase ERK [17], have been shown to interact with BAG3, that can modulate their levels or activity and are therefore potentially involved in BAG3 mechanism of action in these cells.

Recently, it was demonstrated that BAG3 knockdown induces Epithelial Mesenchymal Transition

A

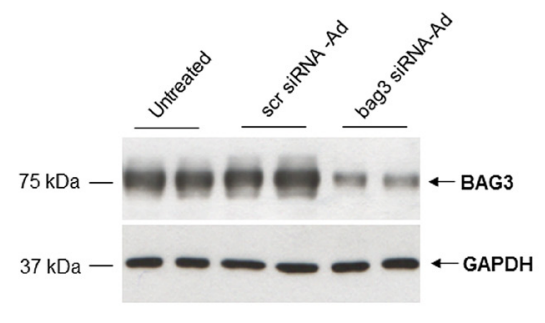

B
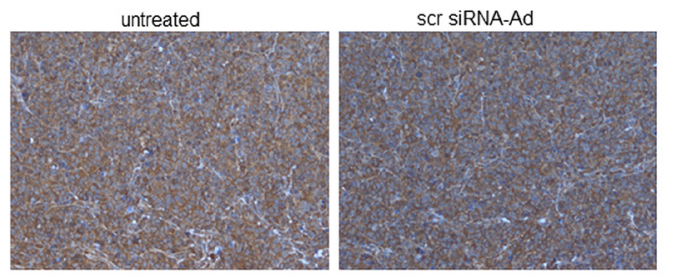

bag3 siRNA-Ad

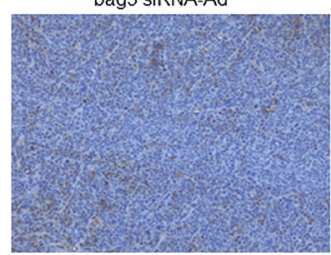

Negative control

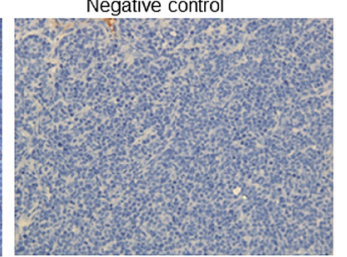

Figure 5: Analysis of BAG3 expression in $\mathbf{H 6 9}$ xenografts. A) Western blot analysis of protein extracted from H69 xenografts treated with PBS $100 \mu \mathrm{l}$ (untreated), scr siRNAAd $\left(10^{8} \mathrm{pfu} / 100 \mu \mathrm{l}\right)$ or bag3 siRNA-Ad $\left(10^{8} \mathrm{pfu} / 100 \mu \mathrm{l}\right)$ by intratumoral injection, twice a week. B) Immunohistochemistry with anti-BAG3 monoclonal of xenograft tumors treated as in A (200x). Negative control: immunostaining of xenografted tumor samples stained without the primary antibody (200x). 
(EMT) in thyroid cancer cells increasing their metastatic potential [18]. However Xiao H. et al. have opposite results and show that BAG3 overexpression is associated with the increased angiogenesis and invasive ability of hepatocellular carcinoma cells [19]. These different results can possibly be explained by the fact that BAG3 can exert different effects depending on the cellular context and therefore on the different proteins it interacts and regulates [4]. Our next aim will be focused on a more deeper understanding of the role of BAG3 in EMT cellular context in orthotopic animal model of SCLC. It is therefore important to study the effects of altered expression of BAG3 in the different contexts to fully understand its biological role. Moreover it is possible that the effect of
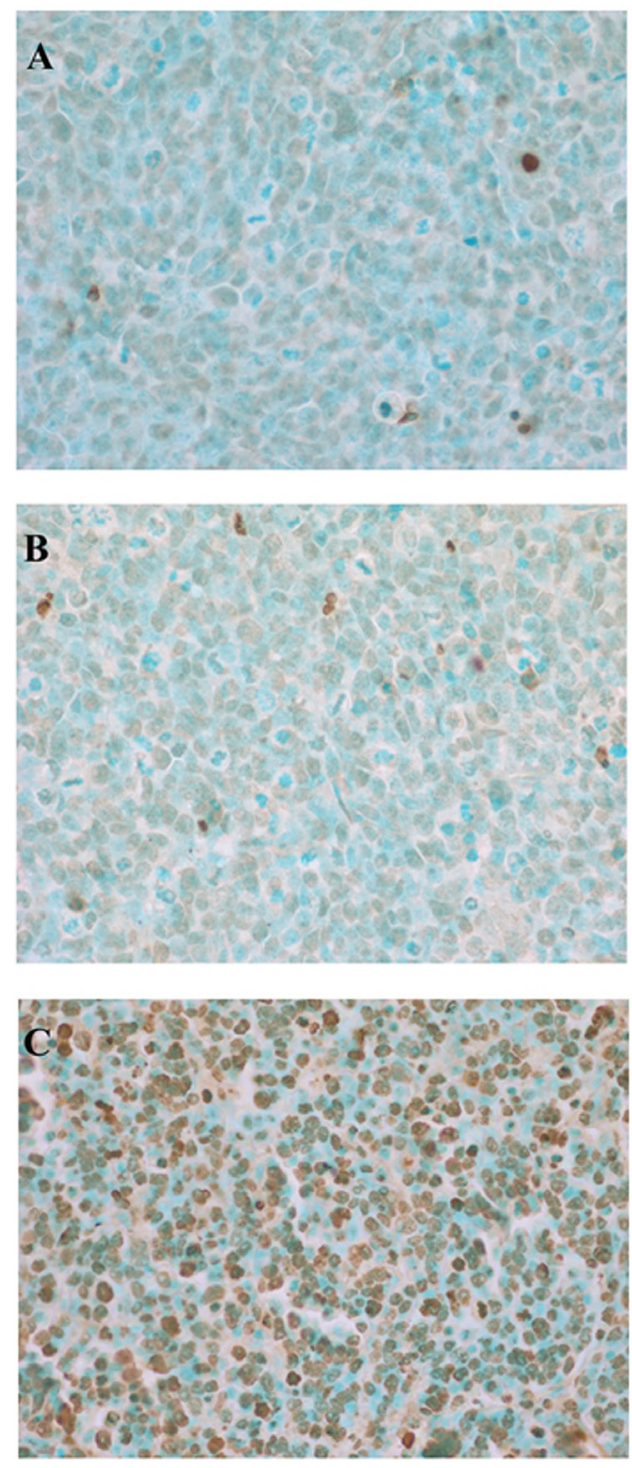

Figure 6: BAG3 down-regulation induces apoptosis in H69-xenografted mice. TdT-FragEL staining of samples from H69 xenografts treated with PBS (untreated-A), scr siRNA-Ad (B) or bag3 siRNA-Ad (C) by intratumoral injection, twice a week.
BAG3 on growth and survival of the primary tumor cell and on EMT and invasive capacity are independent and rely on different signaling pathway so it is possible that while increased BAG3 favors tumor cell survival and growth it prevents EMT and metastatic spreading. While clearly both effects of BAG3 have to be taken in account when proposing a new therapeutic approach, this goes beyond the scope of this manuscript in which we focused on the role of BAG3 on growth and survival of the primary tumor.

In conclusion, our studies show that increased expression of BAG3 in SCLCs represents an advantage for these cells resulting in reduced cell death and increased resistance to therapy and that evaluating BAG3 expression may represent a potential marker of prognosis and of response to cisplatin therapy. Finally, BAG3 could be a novel target for therapy for the subset of SCLCs that overexpress it.

\section{MATERIALS AND METHODS}

\section{Cell lines}

The SCLC cell lines DMS79, H209, H69, H526 and H446 were provided by the American Type Culture Collection and grown in RPMI-1640 medium supplemented with 10\% fetal bovine serum (Cambrex Bio Science), 2mM L-glutamine, 10mM Hepes, $1 \mathrm{mM}$ sodium pyruvate, $1 \%$ penicillin-streptomycin mixture, at $37^{\circ} \mathrm{C}$, in a $5 \%$ CO2 atmosphere.

\section{Reagents}

The polyclonal (TOS-2) and monoclonal (mAb) (AC-1) antibodies against human BAG3 protein were provided by Biouniversa srl, Italy. Anti- GAPDH mAb was obtained from Santa Cruz Biotechnology Inc. Enhanced chemiluminescence Western blot detection reagents were purchased from Amersham Life Sciences Inc. (Pennsylvania Pittsburgh, USA). Secondary antibodies were purchased from Pierce (Meridian Rd, Rockford, IL USA).

\section{siRNAs and adenoviral constructs}

bag3 siRNA (5'-AAGGUUCAGACCAUCU
UGGAA-3') and non targeted (NT) siRNA
(5'-CAGUCGCGUUUGCGACUGG-3') rere
synthesized by Dharmacon (La Fayette, CO). Transfectin
(Bio-Rad Laboratories, Inc., Hercules CA) was used for
cell transfection. bag3 siRNA-Ad and scr siRNA-Ad
were made using the BD Adeno-X Expression Systems
2 PT3674-1 (Pr36024) and BD knockout RNAi Systems


PT3739 (PR42756) (BD Biosciences-Clontech, Palo Alto, CA) [5].

\section{Animals}

Twentyfour six/eight-week-old female athymic nude-Foxn $1^{\text {nu/nu }}$ mice were purchased by Harlan Laboratories S.rl. (S. Pietro al Natisone, Italy). Mice were housed eight per cage and maintained on a $12 \mathrm{hrs}$ light:12 hrs dark cycle (lights on at 7:00 a.m.) in a temperaturecontrolled room $\left(22 \pm 2^{\circ} \mathrm{C}\right)$ with food and water ad libitum. The experimental protocols were in compliance with the European Communities Council directive (86/609/EEC). H69 xenografts were produced on the right flank of the mice by subcutaneous injection of $3 \times 10^{6} \mathrm{H} 69$ cells in $150 \mu \mathrm{l}$ of Hanks' balanced salt solution. Three weeks after tumor cell injection, mice with tumors of similar size (about $100 \mathrm{~mm}^{3}$ ) were randomized into three groups ( 8 mice per group) and treated with control PBS $(100 \mu \mathrm{l})$, bag3 siRNA-Ad or scr siRNA-Ad $\left(10^{8} \mathrm{pfu} / 100\right.$ microl), by peri-tumoral injection, twice a week. Tumor size was measured every three days by digital caliper 2Biol (Besozzo, Varese, Italy) and tumor volumes were calculated according to the formula: $\mathrm{V}=(\mathrm{a} \times \mathrm{b} 2) / 2$, where $a=$ the largest superficial diameter and $b=$ the smallest superficial diameter. When the tumor burden reached $750 \mathrm{~mm}^{3}$ three mice from each group were euthanized to assess the silencing of BAG3 by immunohistochemistry (IHC). All other mice were sacrificed when tumor size reached $1500 \mathrm{~mm}^{3}$ in the control group. Differences among the treatment groups were analyzed by ANOVA using statistical software Graph Pad Prism 5.0 (La Jolla, CA). Survival was analyzed by the Kaplan-Meier method, and survival curves were compared by use of the log-rank test [20].

\section{Immunohistochemistry}

\section{Patients}

The paraffin sections of thirty patients with NSCLC classified according to the degree of differentiation and thirty-six patients with SCLC were selected by the Pathologists of the Istituto Nazionale Tumori, Fondazione G. Pascale, Napoli, Italy.

\section{Xenografts}

Excised tumors were immediately fixed in $10 \%$ neutral buffered formalin and paraffin embedded.

Immunohistochemical staining of human and xenograft tumor sections was performed as follows. Five- to $6-\mu \mathrm{m}$-thick paraffin sections from each tumor were deparaffinised and placed in a solution containing $0.3 \%$ hydrogen peroxide at room temperature. After blocking, the humans and xenografts slides were incubated overnight at $4^{\circ} \mathrm{C}$ in a wet chamber with the anti-BAG3 polyclonal antibody TOS-2 (diluition 1:200 in PBS) and anti-BAG3 monoclonal antibody (mAb) AC-1 (diluition 1:100 in PBS) (Biouniversa Srl, Fisciano, Italy), respectively. Immunoreactivity was visualized using a streptavidin-biotin-peroxidase complex according to the manufacturer's instructions, with diaminobenzidine as peroxidase substrate (Dako REAL ${ }^{\mathrm{TM}}$ Detection System, Peroxidase/DAB ${ }^{+}$, Rabbit/Mouse). The stained sections were counterstained with hematoxylin. Negative controls were performed by omitting the primary antibodies (data not shown).

\section{Western blotting}

Cells were harvested and lysed in a buffer containing $20 \mathrm{mM}$ HEPES (pH 7.5), $150 \mathrm{mM} \mathrm{NaCl}$, $0.1 \%$ Triton (TNN buffer) supplemented with a protease inhibitors cocktail (1 mM phenylmethylsulfonyluoride, 1 $\mathrm{mg} / \mathrm{ml}$ pepstatin A, $2 \mathrm{mg} / \mathrm{ml}$ aprotinin), and subjected to 3 cycles of freeze-and-thawing. Lysates were centrifuged for $20 \mathrm{~min}$ at $12000 \mathrm{rpm}$ and stored at $-80^{\circ} \mathrm{C}$. Protein amount was determined by Bradford assay (Bio-Rad, Hercules, CA) and $30 \mu \mathrm{g}$ of total protein were run on $10 \%$ SDS-PAGE gels and subjected to electrophoretic transfer to a nitrocellulose membrane. Nitrocellulose blots were blocked with $10 \%$ nonfat dry milk in TBST buffer (20 $\mathrm{mM}$ Tris- $\mathrm{HCl}, \mathrm{pH} 7.4$ ), $500 \mathrm{mM} \mathrm{NaCl}$ and $0.01 \%$ Tween, and incubated with primary antibody in TBST containing $5 \%$ nonfat dry milk overnight at $4^{\circ} \mathrm{C}$. Immunoreactivity was detected by sequential incubation with horseradish peroxidase-conjugated secondary antibody and ECL reagents. Scanning densitometry of the bands was performed with image scanning software (SnapScan 1212; Agfa-Gevaert, Mortsel, Belgium). The area under the curve related to each band was determined using Gimp version 2.6 software (http://www.gimp.org). Background was subtracted from the calculated values.

\section{Apoptosis evaluation}

Cells transfected with bag3- specific or NT siRNA (48 hours) were incubated with or without cisplatin at the indicated concentrations. After 48 hour, cells were harvested and then incubated with a propidium iodide (PI) solution $(0.1 \%$ sodium citrate, $0.1 \%$ Triton X-100 and 50 $\mu \mathrm{g} / \mathrm{ml}$ of $\mathrm{PI}$ ), for $30 \mathrm{~min}$ at $4^{\circ} \mathrm{C}$. Apoptosis was quantified as the proportion of cells with hypodiploid DNA (sub G0-G1 peak) using flow cytometry (FACScan Becton Dickinson). A minimum of 5000 events were recorded and analyzed. Cellular debris was excluded from analysis by raising the forward threshold. All measurements were performed using the same instrument settings. Significance between the groups was calculated by unpaired Student's t test. 
Apoptosis on the FFPE (Formalin-Fixed, ParaffinEmbedded tissues) sections from isolated tumor tissues of xenograft, was detected using a TdT-FragEL DNA Fragmentation detection kit (Calbiochem) according to the manufacturer's guidelines.

\section{Statistical analysis}

Results are expressed as means of duplicates \pm SD obtained from three independent experiments. Data were analyzed by Student's t-test using GraphPad Prism statistical software (La Jolla, CA).

Significance was evaluated according to the scale: $* \mathrm{P}<0.05$ (significant); $* * \mathrm{P}<0.01 \quad$ (very significant); $* * * \mathrm{P}<0.001$ (highly significant).

\section{Conflicts of interest}

BIOUNIVERSA s.r.1., which produces anti-BAG3 antibodies, provided them free of charges for this study. $\mathrm{AB}, \mathrm{AF}, \mathrm{AR}, \mathrm{MF}, \mathrm{MP}, \mathrm{VDL}$ and MCT are shareholders of the company BIOUNIVERSA that provided some of the used antibodies. The remaining authors declare no conflict of interest.

\section{ACKNOWLEDGEMENTS}

This work was supported by a grant from the Associazione Italiana Ricerca Cancro (AIRC), Project Investigator Grant (IG) number $I G-12962$ to $G C$; by Italian Ministery for Research and University Grant number ORSA113550 and AIRC IG-14701 to MCT; by Italian Ministery of Health and AIRC $I G-11450$ to $V D L$.

\section{REFERENCES}

1. Früh M, De Ruysscher D, Popat S, Crinò L, Peters S, Felip E; ESMO Guidelines Working Group. Small-cell lung cancer (SCLC): ESMO Clinical Practice Guidelines for diagnosis, treatment and follow-up. Ann Oncol. 2013; 24(6):vi99-105.ù

2. Rossi A, Di Maio M, Chiodini P, Rudd RM, Okamoto H, Skarlos DV, Früh M, Qian W, Tamura T, Samantas E, Shibata T, Perrone F, Gallo C, Gridelli C, Martelli O, Lee SM. Carboplatin- or cisplatin-based chemotherapy in firstline treatment of small-cell lung cancer: the COCIS metaanalysis of individual patient data. J Clin Oncol. 2012; 30(14):1692-8.

3. Rosati A, Basile A, Falco A, d'Avenia M, Festa M, Graziano V, De Laurenzi V, Arra C, Pascale M, Turco MC. Role of BAG3 protein in leukemia cell survival and response to therapy. Biochim Biophys Acta. 2012; 1826(2):365-9.

4. Rosati A, Graziano V, De Laurenzi V, Pascale M and Turco
MC 2011. BAG3: a multifaceted protein that regulates major cell pathways. Cell Death and Disease. 2011; 2(4): e141

5. Ammirante M, Rosati A, Arra C, Basile A, Falco A, Festa M, Pascale M, d'Avenia M, Marzullo L, Belisario MA, De Marco M, Barbieri A, Giudice A, Chiappetta G, Vuttariello E, Monaco M, Bonelli P, Salvatore G, Di Benedetto M, Deshmane SL, Khalili K, Turco MC, Leone A. IKK $\{$ gamma $\}$ protein is a target of BAG3 regulatory activity in human tumor growth. Proc Natl Acad Sci U S A. 2010; 107:7497-7502.

6. Rosati A, Bersani S, Tavano F, Dalla Pozza E, De Marco M, Palmieri M, De Laurenzi V, Franco R, Scognamiglio G, Palaia R, Fontana A, di Sebastiano P, Donadelli M, Dando I, Medema JP, Dijk F, Welling L, di Mola FF, Pezzilli R, Turco MC, Scarpa A. Expression of the antiapoptotic protein BAG3 is a feature of pancreatic adenocarcinoma and its overexpression is associated with poorer survival. Am J Pathol. 2012; 181(5):1524-9.

7. Basile A, Del Gatto A, Diana D, Di Stasi R, Falco A, Festa M, Rosati A, Barbieri A, Franco R, Arra C, Pedone C, Fattorusso R, Turco MC, D'Andrea LD. Characterization of a designed vascular endothelial growth factor receptor antagonist helical peptide with antiangiogenic activity in vivo. J Med Chem. 2011; 10;54(5):1391-400.

8. Franco R, Scognamiglio G, Salerno V, Sebastiani A, Cennamo G, Ascierto PA, Botti G, Turco MC, Rosati A. Expression of the anti-apoptotic protein BAG3 in human melanomas. J Invest Dermatol. 2012; 132(1):252-4.

9. Festa M, Del Valle L, Khalili K, Franco R, Scognamiglio G, Graziano V, De Laurenzi V, Turco MC, Rosati A. BAG3 protein is overexpressed in human glioblastoma and is a potential target for therapy. Am J Pathol. 2011; 178(6):2504-12.

10. Chiappetta G, Basile A, Arra C, Califano D, Pasquinelli R, Barbieri A, De Simone V, Rea D, Giudice A, Pezzullo L, De Laurenzi V, Botti G, Losito S, Conforti D, Turco MC.BAG3 down-modulation reduces anaplastic thyroid tumor growth by enhancing proteasome-mediated degradation of BRAF protein. J Clin Endocrinol Metab. 2012; 97(1):E115-20.

11. Hensing T, Chawla A, Batra R, Salgia R. A personalized treatment for lung cancer: molecular pathways, targeted therapies, and genomic characterization. Adv Exp Med Biol. 2014; 799:85-117.

12. Arriola E, Cañadas I, Arumí-Uría M, Dómine M, LopezVilariño JA, Arpí O, Salido M, Menéndez S, Grande E, Hirsch FR, Serrano S, Bellosillo B, Rojo F, Rovira A, Albanell J. MET phosphorylation predicts poor outcome in small cell lung carcinoma and its inhibition blocks HGFinduced effects in MET mutant cell lines. J. Cancer. 2011; 105(6):814-23.

13. Tretiakova M, Salama AK, Karrison T, Ferguson MK, Husain AN, Vokes EE, Salgia R. MET and phosphorylated MET as potential biomarkers in lung cancer. J Environ 
Pathol Toxicol Oncol. 2011; 30(4):341-54.

14. Rolle CE, Kanteti R, Surati M, Nandi S, Dhanasingh I, Yala S, Tretiakova M, Arif Q, Hembrough T, Brand TM, Wheeler DL, Husain AN, Vokes EE, Bharti A, Salgia R. Combination MET inhibition and Topoisomerase I inhibition block cell growth of Small Cell Lung Cancer. Mol Cancer Ther. 2014; 13(3):576-84

15. Cañadas I, Rojo F, Taus A, Arpí O, Arumí-Uría M, Pijuan L, Menéndez S, Zazo S, Dómine M, Salido M, Mojal S, García de Herreros A, Rovira A, Albanell J, Arriola E. Targeting Epithelial-to-Mesenchymal Transition with Met Inhibitors Reverts Chemoresistance in Small Cell Lung Cancer. Clin Cancer Res. 2014; 15;20(4):938-50

16. Graveel CR, Tolbert D, Vande Woude GF. MET: a critical player in tumorigenesis and therapeutic target. Cold Spring Harb Perspect Biol. 2013; 1;5(7).

17. Falco A, Rosati A, Festa M, Basile A, De Marco M, d'Avenia M, Pascale M, Dal Piaz F, Tavano F, Di Mola FF, di Sebastiano P, Berloco PB, Nudo F, Caraglia M, Febbraro A, Barcaroli D, Scarpa A, Pezzilli R, De Laurenzi V, Turco MC. BAG3 is a novel serum biomarker for pancreatic adenocarcinomas. Am J Gastroenterol. 2013; 108(7):117880 .

18. Meng X, Kong DH, Li N, Zong ZH, Liu BQ, Du ZX, Guan Y, Cao L, Wang HQ. Knockdown of BAG3 induces epithelial-mesenchymal transition in thyroid cancer cells through ZEB1 activation. Cell Death Dis. 2014; 27;5:e1092.

19. Xiao H, Cheng S, Tong R, Lv Z, Ding C, Du C, Xie H, Zhou $\mathrm{L}$, Wu J, Zheng S. BAG3 regulates epithelial-mesenchymal transition and angiogenesis in human hepatocellular carcinoma. Lab Invest. 2014; 94(3):252-61.

20. Hosmer, D,W;Lemeshow, S.and May, S. Applied survival analysis; Regression modeling of time-to-event data, 2nd ed; Hoboken, NJ: Wiley, 2008.1-66. 